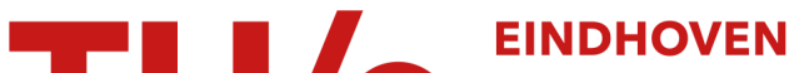 UNIVERSITY OF TECHNOLOGY
}

\section{Optically controlled low-distortion delay of $\mathrm{GHz}$-wide radio- frequency signals using slow light in fibers}

Citation for published version (APA):

Zadok, A., Raz, O., Eyal, A., \& Tur, M. (2007). Optically controlled low-distortion delay of GHz-wide radiofrequency signals using slow light in fibers. IEEE Photonics Technology Letters, 19(7), 462-464.

https://doi.org/10.1109/LPT.2007.891980

DOI:

10.1109/LPT.2007.891980

Document status and date:

Published: 01/01/2007

Document Version:

Publisher's PDF, also known as Version of Record (includes final page, issue and volume numbers)

Please check the document version of this publication:

- A submitted manuscript is the version of the article upon submission and before peer-review. There can be important differences between the submitted version and the official published version of record. People interested in the research are advised to contact the author for the final version of the publication, or visit the $\mathrm{DOI}$ to the publisher's website.

- The final author version and the galley proof are versions of the publication after peer review.

- The final published version features the final layout of the paper including the volume, issue and page numbers.

Link to publication

\section{General rights}

Copyright and moral rights for the publications made accessible in the public portal are retained by the authors and/or other copyright owners and it is a condition of accessing publications that users recognise and abide by the legal requirements associated with these rights.

- Users may download and print one copy of any publication from the public portal for the purpose of private study or research.

- You may not further distribute the material or use it for any profit-making activity or commercial gain

- You may freely distribute the URL identifying the publication in the public portal.

If the publication is distributed under the terms of Article $25 \mathrm{fa}$ of the Dutch Copyright Act, indicated by the "Taverne" license above, please follow below link for the End User Agreement:

www.tue.nl/taverne

Take down policy

If you believe that this document breaches copyright please contact us at:

openaccess@tue.nl

providing details and we will investigate your claim. 


\title{
Optically Controlled Low-Distortion Delay of GHz-Wide Radio-Frequency Signals Using Slow Light in Fibers
}

\author{
Avi Zadok, Oded Raz, Avishay Eyal, Senior Member, IEEE, and Moshe Tur, Fellow, IEEE
}

\begin{abstract}
Continuously tunable delay of broadband analog signals for microwave photonics applications is described and demonstrated, based on stimulated Brillouin scattering (SBS) in optical fibers. The optical spectrum of the pump laser is synthesized using chirp control, in order to obtain a broadened SBS "slow light" process, with long delay and low amplitude and phase distortions. The resulting SBS process is applied to delay 1-GHz-wide linear frequency modulated radio-frequency signals of arbitrary carrier frequency. Delays up to 230 ps are observed, with a worst-case sidelobe suppression ratio of $-26 \mathrm{~dB}$.
\end{abstract}

Index Terms-Microwave photonics, optical antenna beamforming, optical signal processing, slow light, stimulated Brillouin scattering (SBS).

\section{INTRODUCTION}

V ARIABLE delay of analog signals in radar systems is a promising potential application for photonic processing [1]. In these systems, the directional stirring of the transmitted beam is achieved through control of the delay between the signals feeding neighboring elements, in an array of antennas [2]. The delay lines used must accommodate broadband signals with stringent distortion tolerances. Photonic processing implementations are appealing due to their very large usable bandwidth, low frequency-independent loss, immunity to electromagnetic interference, and parallelism through wavelength multiplexing [1]. Several techniques for discrete photonic true time delay (TTD) have been proposed, using multiwavelength sources in conjunction with discretely reconfigurable dispersion [3], [4], or a tunable laser feeding wavelength demultiplexers [5]. Continuously variable delay has been achieved using chirped Bragg gratings [6], but the accompanying non-zero dispersion can distort even single-sideband (SSB) modulated signals [7].

A large number of works had recently demonstrated continuously variable, optically controlled delay lines, based on the large phase variations which accompany resonant gain or absorption peaks [8]. These phenomena are largely referred to in the literature as "slow and fast light." Of the various mechanisms used in optical fiber-based implementations, stimulated

Manuscript received November 27, 2006; revised January 8, 2007. This work was supported in part by the Israel Science Foundation. The work of A. Zadok was supported by the Israel Clore Foundation under a Ph.D. study scholarship.

A. Zadok, A. Eyal, and M. Tur are with the Faculty of Engineering, Tel-Aviv University, Tel Aviv 69978, Israel (e-mail: avinoamz@ post.tau.ac.il).

O. Raz was with the Faculty of Engineering, Tel-Aviv University, Tel Aviv 69978, Israel. He is now with the Department of Electrical Engineering, Technical University of Eindhoven, 5600 MB Eindhoven, The Netherlands.

Color versions of one or more of the figures in this letter are available online at http://ieeexplore.ieee.org.

Digital Object Identifier 10.1109/LPT.2007.891980
Brillouin scattering (SBS) appears to be the most promising and thoroughly studied one, due to its robustness, low threshold power, and operational simplicity [9], [10]. With proper modulation of the pump laser, the usable bandwidth of SBS-induced variable delay lines may be extended up to $12 \mathrm{GHz}$ [11], [12], although careful consideration must be given to the extent of accompanying signal distortion [10].

While the major driving force behind slow light related research has been the buffering and synchronization of digital data, its continuous, all-optical delay capabilities are highly attractive for optical antenna beam forming [13], [14]. Recently, long delays of several-megahertz-wide signals were demonstrated [14]. However, no attempt has been made yet to examine the delay performance of actual broadband analog signals, typical of radar systems. In this letter, SBS is applied to successfully delay 1-GHz-wide linear frequency modulation (LFM) signals, carried upon an intermediate frequency (IF) of $5 \mathrm{GHz}$. Signals of this type are widely used in radar systems to obtain high temporal resolution, while avoiding the need for short pulses of high peak power [2]. The SBS process bandwidth was broadened using a carefully tailored direct modulation of the pump laser, designed to extend delay and minimize signal distortion [12].

\section{PUMP SPECTRUM Synthesis}

The gain and phase response of the probe signal in SBS is controlled by the complex gain function $g(\omega)$ [11]

$$
\left.E_{\text {sig }}(\omega)\right|_{\text {out }}=\left.E_{\text {sig }}(\omega)\right|_{\text {in }} \exp [g(\omega) / L / 2]
$$

where $E_{\mathrm{sig}}(\omega)$ denotes the probe signal, $L$ is the fiber effective length, and $\omega$ the optical frequency of the probe. $g(\omega)$ is a convolution of the pump laser spectrum $I_{p}\left(\omega_{p}\right)$, with the $\gamma_{B} / 2 \pi \sim$ $30 \mathrm{MHz}$ wide Lorenzian gain function of SBS with continuous-wave (CW) pump [11]. When the width of $I_{p}\left(\omega_{p}\right)$ is much larger than $\gamma_{B}, \operatorname{Re}[g(\omega)]$ is proportional to $I_{p}(\omega)$, down-shifted by $\Omega_{B} / 2 \pi \sim 11 \mathrm{GHz} . \operatorname{Im}[g(\omega)]$ can be derived from $\operatorname{Re}[g(\omega)]$, using the Kramers-Kronig relations [11], [12].

Using the above relations, the SBS complex response can be calculated for a given $I_{p}\left(\omega_{p}\right)$. For the application of TTD, $I_{p}\left(\omega_{p}\right)$ should be chosen so that $\operatorname{Re}[g(\omega)]$ is nearly constant over a frequency band $\Delta \omega$, and $\operatorname{Im}[g(\omega)]$ follows closely a linear fit, preferably with a steep slope. To that end, $I_{p}\left(\omega_{p}\right)$ is required to be nearly uniform within $\Delta \omega$, with sharp spectral edges [12], [15].

The spectrum of the pump laser diode is broadened and manipulated using direct modulation of the injection current, taking advantage of the mechanisms of adiabatic and thermal chirp. The chirp response of distributed feedback (DFB) lasers and the 


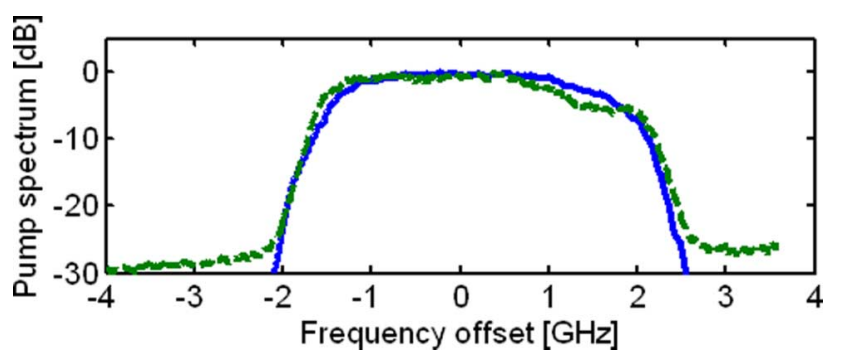

Fig. 1. Measured (dashed) and simulated (solid) relative power spectra of pump DFB laser, directly modulated by the waveform of (2).

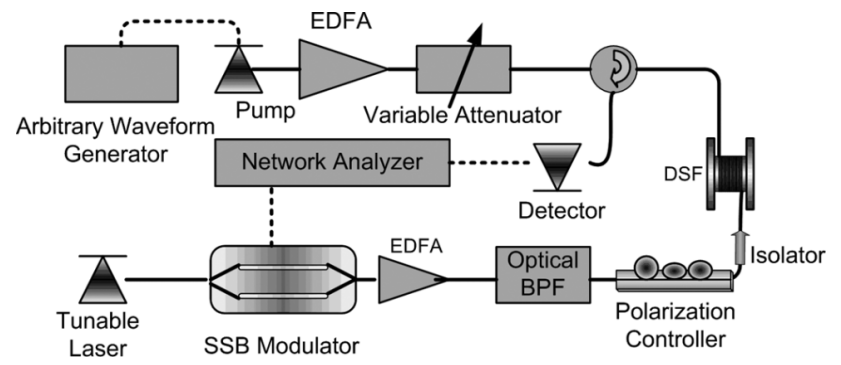

Fig. 2. VNA measurements setup for of SBS gain and phase response.

modulation synthesis procedure were detailed in our previous work and references therein [12]. The current modulation function was synthesized to be of the form [12]

$$
i(t)=i_{0}+\Delta i\left[1-(t \bmod T / T)^{1.5}\right]+i_{N}(t)
$$

where $i_{0}=80 \mathrm{~mA}$ the bias current, $\Delta i=11 \mathrm{~mA}$, and $T=$ $320 \mathrm{~ns}$ denoting the magnitude and period of a deterministic periodic modulation term, and $i_{N}(t)$ representing a random modulation component of Gaussian statistics, bandwidth of $20 \mathrm{MHz}$ and root-mean-square (rms) magnitude of $1.6 \mathrm{~mA}$. The pump power spectrum was measured by beating the modulated laser with a second, $\mathrm{CW}$ laser on a detector, and observing the result with a radio-frequency (RF) spectrum analyzer. Good agreement between measurement and simulation is seen in Fig. 1, with a uniform spectrum over a 2-GHz-wide frequency range. The obtained pump spectrum is suitable for delaying broadband signals, as described below.

\section{Vector Network ANalyzer (VNA) Measurements}

The gain and phase response of the SBS process were measured using a VNA (Fig. 2) [16]. The pump signal was that of the DFB laser of the previous section, directly modulated by a properly programmed arbitrary waveform generator and amplified by a high-power fiber amplifier. A circulator directed the pump signal into $20 \mathrm{~km}$ of dispersion-shifted fiber (DSF). A stable tunable laser was used as a probe signal source, connected to an $\mathrm{SSB} \mathrm{LiNbO}_{3}$ MZI modulator. Using the VNA, the upshifted modulation sideband scanned the broadened SBS gain curve over a $2-8-\mathrm{GHz}$ range, while the probe carrier frequency was adjusted to fall below this curve. The VNA detected the beating between carrier and sideband, which was proportional to the SBS frequency response [16]. Measurements were taken at different pump power levels.

Fig. 3 (top) shows an example of the measured SBS probe power gain, alongside a calculated curve which was based on
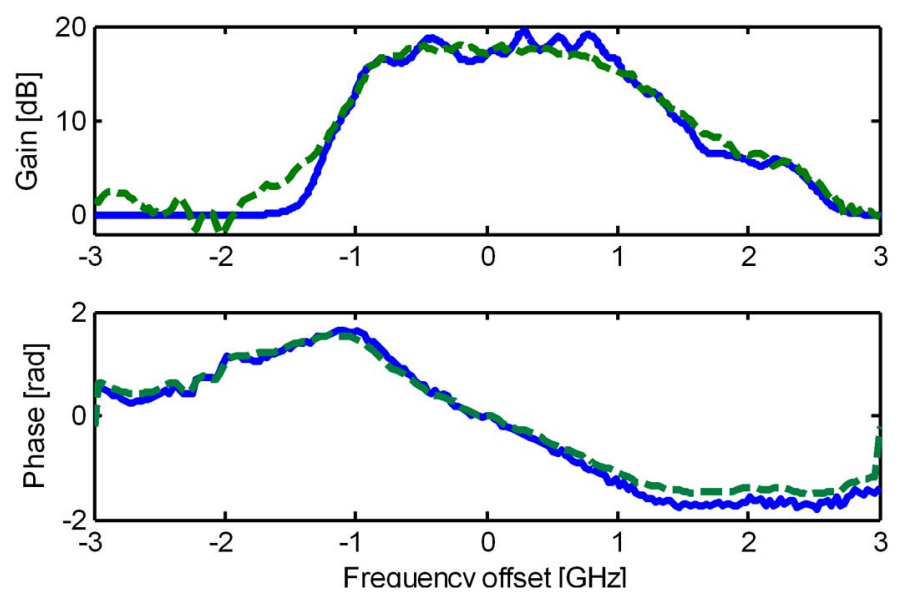

Fig. 3. Top: VNA measured (dashed) and calculated (solid) SBS probe optical power gain. Bottom: VNA measured (dashed) and calculated (solid) SBS probe optical phase response. Pump power was $20 \mathrm{dBm}$.

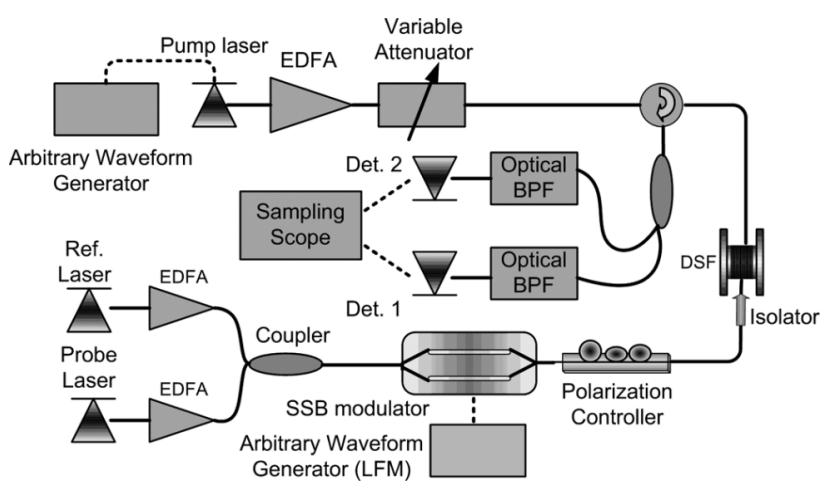

Fig. 4. Measurement setup for SBS induced delay of LFM signals.

Fig. 1. The gain is nearly uniform over a range of $2 \mathrm{GHz}$, as expected. An example of the phase response is shown on the bottom of Fig. 3, together with a prediction, derived from the measured gain and the Kramers-Kronig relations. The probe phase closely follows a linear fit, suggesting the ability to delay broadband signals with little phase distortion. The delay in the specific example, calculated as the slope of the phase response within the gain bandwidth, was found to be $120 \mathrm{ps}$. The SBS process was used next to delay 1-GHz-wide LFM signals.

\section{DELAY OF BROADBAND LFM Signals}

The setup for characterizing the SBS-induced delay of LFM signals is shown in Fig. 4. The pump-wave generation is the same as that of the previous section. The SSB MZI modulator driving voltage was that of an LFM signal with bandwidth $B=$ $1 \mathrm{GHz}$ and duration $T=20 \mu \mathrm{s}$, superimposed upon an RF carrier $f_{0}=5 \mathrm{GHz}$

$$
V_{\mathrm{LFM}}(t) \propto \cos \left[2 \pi f_{0} t+(\pi B / T) t^{2}\right] \cdot \operatorname{rect}(t / T) .
$$

During the pulse life $(-T / 2 \leq t \leq T / 2)$, the instantaneous frequency linearly scans the range $f_{0}-B / 2 \leq f \leq f_{0}+B / 2$. With proper subsequent processing, the detected pulse can be compressed to a temporal width of $\sim 1 / B \ll T$ [2], [7], yielding high-range resolution in a radar system, while alleviating the need for transmitting short high-power pulses. 

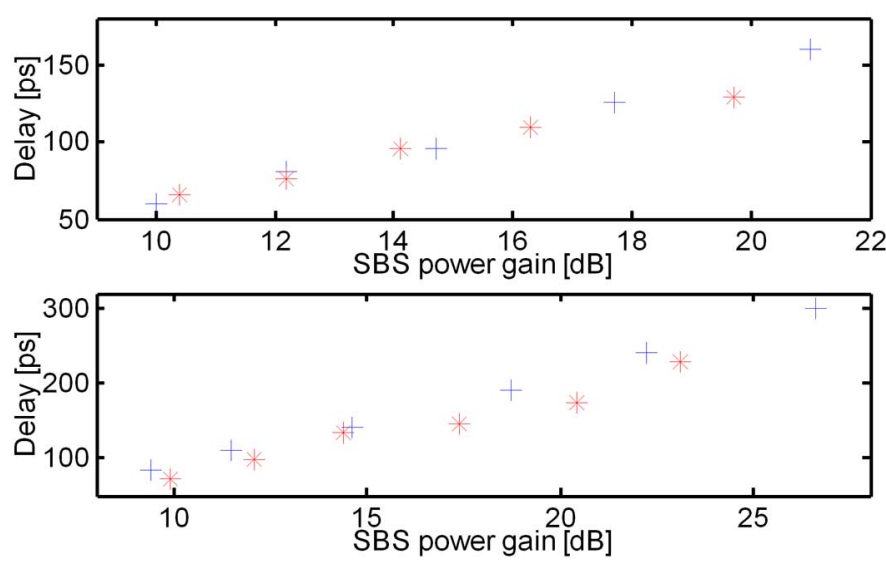

Fig. 5. SBS-induced delay versus probe power gain. Plus signs: VNA data. Asterisk signs: 1-GHz-wide LFM signals data. Top: 20-km DSF, pump power 17-21 dBm. Bottom: 3.5-km HNLF, pump power 16-21 dBm.

The optical frequency of the probe laser was adjusted so that its upshifted LFM-modulated sideband overlapped the gain bandwidth of the SBS process. Consequently, the LFM signal of this laser was amplified and delayed by SBS, whereas a co-modulated second laser, detuned by $10 \mathrm{~nm}$, was unaffected and served as a timing reference. Following propagation, the two optical signals were individually filtered, detected, and down-converted to an IF of $1 \mathrm{GHz}$. The resulting waveforms were sampled by a dual-channel 4-GHz real-time digitizing oscilloscope, and processed to obtain the appropriate compressed pulse [2], [7], from which the SBS gain and delay could be evaluated.

Fig. 5 (top) shows the measured delay versus gain of the LFM signal, alongside predictions based on the VNA measurements. The delay increases linearly with the signal power gain, reaching a maximum of $130 \mathrm{ps}$ at a pump power of $21 \mathrm{dBm}$. In a second set of measurements, $3.5 \mathrm{~km}$ of highly nonlinear fiber (HNLF) replaced the DSF (bottom of Fig. 5). Using the HNLF, a maximum delay of 230 ps was achieved for the same pump power. For both fibers, general agreement between the delay of LFM signals and the predictions based on VNA measurements is evident. The worst-case peak sidelobe ratio of the compressed pulses was $-26 \mathrm{~dB}$ [7], and the $-20-\mathrm{dB}$ width of the main lobe increased by less than $1 \%$.

The dynamic range of this SBS-based TTD implementation will be eventually limited by spontaneous Brillouin scattering [17]. However, for LFM signals, the signal-to-noise, as defined by the ratio of the peak of the compressed signal to the noise level, can be arbitrarily increased using longer pulses. In some microwave applications, the integrated sidelobe ratio (energy in the main lobe over energy elsewhere) is the important figure of merit. While it does not depend on the pulse duration, our experiment yielded a value large than $21 \mathrm{~dB}$, which is more than adequate for most applications.

In conclusion, a novel photonic implementation of continuously variable, wideband, and low distortion TTD was demonstrated using slow light techniques. Note that the use of
SSB modulation facilitates the handling of arbitrarily high RF carrier frequencies. Also, wider bandwidths may be accommodated at the expense of shorter delays [11]. While SBS slowlight-induced delay is currently insufficient for large-scale data buffering [15], it may be quite applicable to many microwave applications. For example, it can provide enough beam-stirring to bridge the gap between discrete microwave photonic delays in large scale phased array antennas [3]-[5], [13].

\section{ACKNOWLEDGMENT}

The authors would like to thank S. Barzilay for her assistance in the experimental work.

\section{REFERENCES}

[1] J. Capmany, B. Ortega, D. Pastor, and S. Sales, "Discrete-time optical processing of microwave signals," J. Lightw. Technol., vol. 23, no. 2, pp. 702-723, Feb. 2005.

[2] P. Lacomme, J.-P. Hardange, J.-C. Marchais, and E. Normant, Air and Spaceborne Radar Systems. Norwich, NY: William Andrew, 2001.

[3] D. T. K. Tong and M. C. Wu, "Multiwavelength optically controlled phased array antennas," IEEE Trans. Microw. Theory Tech., vol. 46, no. 1, pp. 108-115, Jan. 1998.

[4] M. A. Piqueras, G. Grosskopf, B. Vidal, J. Herrera, J. M. Martinez, P. Sanchis, V. Polo, J. L. Corral, A. Marceaux, J. Galiere, J. Lopez, A. Enard, J.-L. Valard, O. Parillaud, E. Estebe, N. Vodjdani, M.-S. Choi, J. H. den Besten, F. M. Soares, M. K. Smit, and J. Marti, "Optically beamformed beam-switched adaptive antennas for fixed and mobile broadband wireless access networks," IEEE Trans. Microw. Theory Tech., vol. 54, no. 7, pp. 887-899, Feb. 2006.

[5] O. Raz, R. Rotman, and M. Tur, "Wavelength-controlled photonic true time delay for wideband applications," IEEE Photon. Technol. Lett., vol. 17, no. 5, pp. 1076-1078, May 2005.

[6] J. L. Cruz, B. Ortega, M. V. Andres, B. Gimeno, D. Pastor, J. Capmany, and L. Dong, "Chirped fiber Bragg gratings for phased array antennas," Electron. Lett., vol. 33, pp. 545-546, Mar. 1997.

[7] R. Rotman, O. Raz, and M. Tur, "Analysis of a true time delay photonic beamformer for transmission of a linear frequency modulated waveform," J. Lightw. Technol., vol. 23, no. 12, pp. 4026-4036, Dec. 2005.

[8] R. W. Boyd and D. J. Gauthier, "Slow and fast light," in Progress in Optics, E. Wolf, Ed. Amsterdam: Elsevier, 2002, vol. 43, pp. 497-530.

[9] M. González-Herráez, K.-Y. Song, and L. Thévenaz, "Optically controlled slow and fast light in optical fibers using stimulated Brillouin scattering," Appl. Phys. Lett., vol. 87, p. 081113, Aug. 2005.

[10] M. D. Stenner, M. A. Neifeld, Z. Zhu, A. M. C. Dawes, and D. J. Gauthier, "Distortion management in slow-light pulse delay," Opt. Express, vol. 13, pp. 9995-10002, Dec. 2005.

[11] Z. Zhu, A. M. C. Dawes, D. J. Gauthier, L. Zhang, and A. E. Willner, "12-GHz-bandwidth SBS slow light in optical fibers," in Proc. OFC/ NFOES 2006, Anaheim, CA, Mar. 2006, Paper PDP1.

[12] A. Zadok, A. Eyal, and M. Tur, "Extended delay of broadband signals in stimulated Brillouin scattering slow light using synthesized pump chirp," Opt. Express, vol. 14, pp. 8498-8505, Sep. 2006.

[13] S. Sales, F. Ohman, A. Bermejo, J. Mork, and J. Capmany, "Slow and fast light in SOA-EA structures for phased array antennas," in Proc. ECOC 2006, Cannes, France, Sep. 2006, Paper We.3.61.

[14] L. Gao, S. I. Herriot, and K. H. Wagner, "Sluggish light for radiofrequency true-time-delay applications with a large delay-bandwidth product," Opt. Lett., vol. 31, pp. 3360-3362, Nov. 2006.

[15] J. B. Khurgin, "Performance limits of delay lines based on optical amplifiers," Opt. Lett., vol. 31, pp. 948-950, Apr. 2006.

[16] A. Loayssa, D. Benito, and M. J. Grade, "High resolution measurement of stimulated Brillouin scattering spectra in single-mode fibers," Proc. Inst. Elect. Eng., Optoelectron., vol. 148, pp. 143-148, Jun. 2001.

[17] R. W. Tkach, A. R. Chraplyvy, and R. M. Derosier, "Performance of WDM network based on stimulated Brillouin scattering," IEEE Photon. Technol. Lett., vol. 1, no. 5, pp. 111-113, May 1989. 